\title{
Metallic Pollutants in Sargassum of Cancún, Quintana Roo, México Coast
}

González-Mancera G. ${ }^{1}$, Tehuacanero-Cuapa S. ${ }^{2 *}$ Chavira E. ${ }^{3}$

1. Metallurgy Department/Chemistry Faculty, National Autonomous University of Mexico, México.

2. Central Microscopy Lab./ Physics Institute, National Autonomous University of Mexico, México.

3. Department of Low Dimensionality Materials/ Material Research Institute, National Autonomous University of Mexico, México.

*Corresponding author: ggm@unam.mx

The Sargassum is a generally planktonic alga very common in the Sargasso Sea. It naturally contains bromine, iodine and salts in the form of bromides and iodides. This seaweed never adheres to the seafloor during its life cycle. The Mexican Caribbean coast received unprecedent massive amounts of sargassic algae Sargassum fluitans and S. natans from early summer of 2014 to the beginning of the winter of 2015 [1]. These algae decompose on beaches and coastal waters affect coastal ecosystems, human health and industry tour. Given the innumerable problems associated with the stranded Sargassum, there is a need to sustainable manage marine algae and reduce coastal management. Research conducted to date has revealed several potential uses of Sargassum, such as fertilizer, compost, livestock, fish food, etc. [2]. Therefore, it is considered important to know if this seaweed has any contaminant harmful to its use. Which may have adhered to him during this stay at sea. The aim of this paper is contributing to determinate the adsorption of metallic contaminants in structure like a sargassum leaf. Thus, the whole leaves and seaweed were processed according of standard technique for Scanning Electron Microscopy (SEM) and analyzed by EDS-X ray, in addition ICP-MS was applied. The result shows in the structure similar bladder the presence of elements, in order of occurrence greater than minor, such as: iron, chromium, aluminum, silver, zirconium, and antimony. What matches most elements detected by ICPM throughout his body.

These results suggest that the leaf-like structure of Sargassum of Quintana Roo Coast, does not have dangerous metallic elements adsorbed. However, the continuation of this study includes performing analyzes on its other vegetative structures to determinate their presence [3].

\section{References:}

[1] Rodríguez-Martínez R.E., Tussenbroek B. and Dahlgren E. In "Florecimientos Algales Nocivos en México", ed. García-Mendoza E. et al., (CICESE; Ensenada, 2016) p. 352-365.

[2] Sargassum Management Brief UWI Cave Hill, https://www.cavehill.uwi.edu/cermes/getdoc (0204, 2019)

[3] The authors acknowledge Dr. Jesus Arenas of the LCM-IFUNAM for his support in the analysis of SEM. 

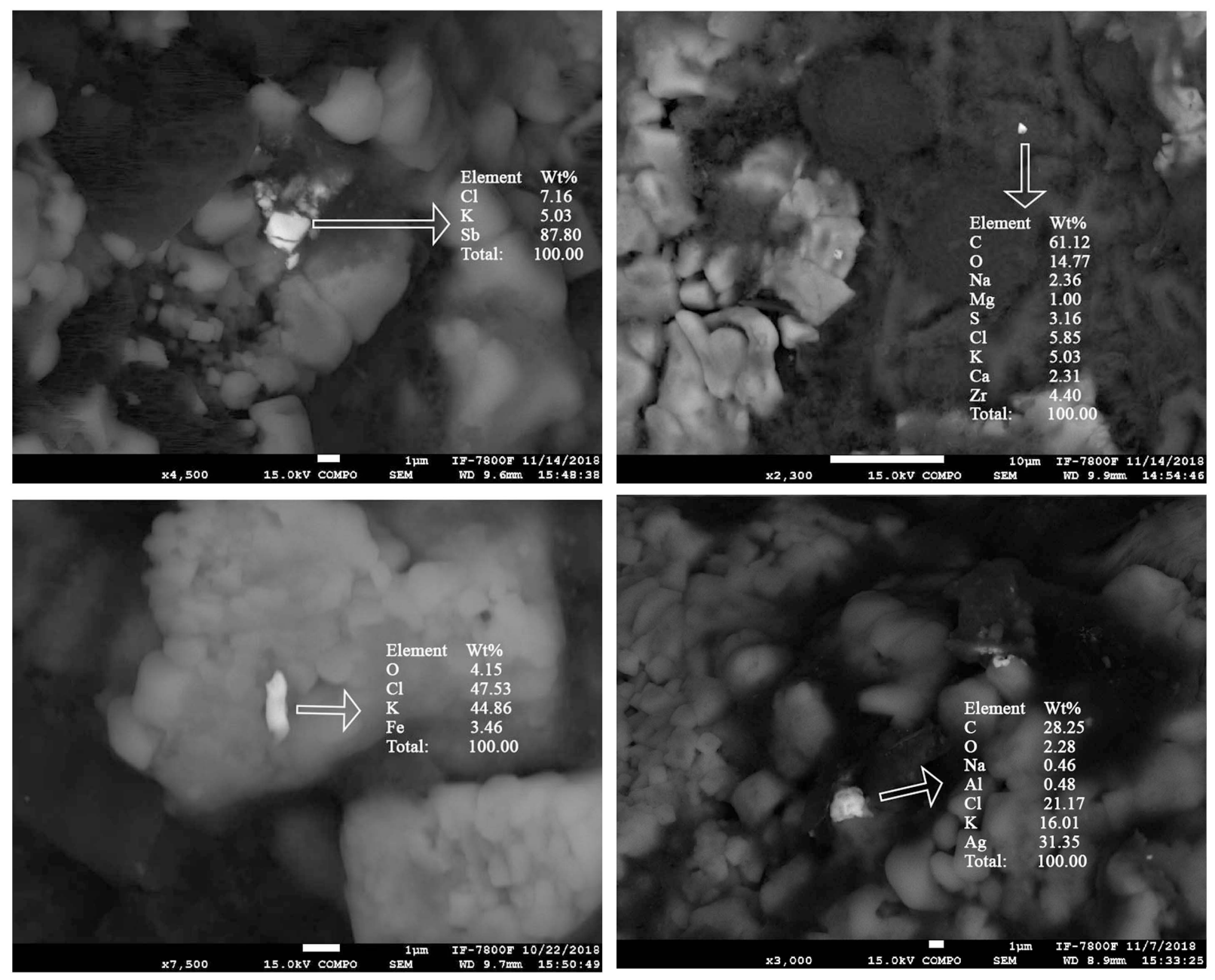

Figure 1. Different areas of the sargassum were analyzed and several metal particles were found. Their chemical composition is showed in white signs. 